\title{
Development of SBR-Nanoclay Composites with Epoxidized Natural Rubber as Compatibilizer
}

\author{
R. Rajasekar, ${ }^{1}$ Gert Heinrich, ${ }^{2}$ Amit Das, ${ }^{2}$ and Chapal Kumar Das ${ }^{1}$ \\ ${ }^{1}$ Materials Science Centre, Indian Institute of Technology, Kharagpur 721 302, India \\ ${ }^{2}$ Department of Composite, Leibniz-Institute of Polymer Research Dresden, Hohe Straße 6, 01069 Dresden, Germany
}

Correspondence should be addressed to Chapal Kumar Das, chapal12@yahoo.co.in

Received 26 April 2009; Accepted 20 May 2009

Recommended by Jaime Grunlan

The significant factor that determines the improvement of properties in rubber by the incorporation of nanoclay is its distribution in the rubber matrix. The simple mixing of nonpolar rubber and organically modified nanoclay will not contribute for the good dispersion of nanofiller in the rubbery matrix. Hence a polar rubber like epoxidized natural rubber (ENR) can be used as a compatibilizer in order to obtain a better dispersion of the nanoclay in the matrix polymer. Epoxidized natural rubber and organically modified nanoclay composites (EC) were prepared by solution mixing. The nanoclay employed in this study is Cloisite 20A. The obtained nanocomposites were incorporated in styrene butadiene-rubber (SBR) compounds with sulphur as a curing agent. The morphology observed through X-ray diffraction (XRD) and high-resolution transmission electron microscopy (HRTEM) shows that the nanoclay is highly intercalated in ENR, and further incorporation of EC in SBR matrix leads to partial exfoliation of the nanoclay. Dynamic mechanical thermal analysis showed an increase in storage modulus and lesser damping characteristics for the compounds containing EC loading in SBR matrix. In addition, these compounds showed improvement in the mechanical properties.

Copyright (c) 2009 R. Rajasekar et al. This is an open access article distributed under the Creative Commons Attribution License, which permits unrestricted use, distribution, and reproduction in any medium, provided the original work is properly cited.

\section{Introduction}

Reinforcement of polymer with nanosized particles is a promising technique that affords to enhanced performance of the materials. Montmorillonite (MMT) is the most commonly used layered silicate because of its natural occurrence and beneficial properties. This filler has drawn a great deal of attention, when layered silicates were dispersed in the polymer matrix at the nanoscale level and the reinforcement ability was improved by replacing the inorganic exchange cations in the galleries of the clay by alkyl ammonium surfactants. It is composed of silicate layers with thicknesses $1 \mathrm{~nm}$, interlayers spacing between the stacked layers of about $1 \mathrm{~nm}$ and very high aspect ratios [1]. Incorporation of very small fraction of the silicate nanofiller would give significant improvements in the stiffness and strength of the related materials. A lot of works have been done in clay nanocomposites for many thermoplastics and thermosetting polymers, but the studies on rubber-based nanocomposites constitute in lesser dimension [2].
The achievement of highly dispersed organoclay nanocomposites involves two main faces. The first face involves the compatibility between the polymer and nanoclay. Organoclay can be more easily dispersed in polar polymers than in nonpolar ones, like NR and SBR. The formulas of organoclay/polar polymeric systems usually contain a polymeric compatibilizer [3]. The compatibilizer is compatible with the matrix polymer, but at the same time it should be highly polar than the matrix. ENR obtained by epoxidation of 1, 4-polyisoprene, depicts a higher glass transition temperature and increased polarity than that of SBR. Accordingly, as a fine dispersion of organoclay is expected, the ENR which depicts high polarity has been chosen in this study. A very few resplendent works have been carried out using ENR as compatibilizer for organoclay/natural rubber nanocomposites by Arroyo et al. [4], Teh et al. [5] and Varghese et al. [6]. From our laboratory, we have already analyzed the effect of ENR as a compatibilizer in natural rubber-nanoclay gum compounds [7] and in presence of carbon black [8], nitrile butadiene rubber-nanoclay composites [9]. 
The second face is the method adopted for the preparation of nanocomposites. Several methods have been used for the preparation of rubber/organoclay nanocomposites, which includes in situ polymerization intercalation [10], solution intercalation [11], melt intercalation [5], finally cocoagulation of rubber latex and clay aqueous suspension [12]. In this study, incorporation of nanoclay in ENR was done by solution mixing, in order to obtain a better dispersion of the nanoclay in ENR. In the obtained ENR-nanoclay composites (EC) were incorporated in the SBR matrix with sulphur as a curing agent. The changes obtained in the morphology and mechanical properties have been analyzed.

\section{Materials}

Styrene butadiene rubber (Grade: 1502) containing 23.5\% styrene content was supplied from Korea Kumbo Petrochemicals Co., Ltd.

Epoxidized natural rubber containing $50 \mathrm{~mol} \%$ epoxidic units was supplied from Agricultural Product Processing Research Institute, Zhangiang, China (specific gravity, 1.03).

Cloisite 20A, a natural montmorillonite modified with a quaternary ammonium salt with cation exchange capacity of 95 mequiv./100 g clay (Southern Clay, Inc., USA), was used as a nanofiller in the preparation of the nanocomposites.

\section{Methods}

3.1. Solution Mixing. ENR was dissolved in toluene. The ratio of the rubber to solvent was $1: 3$, weight/volume. The solution was continually stirred at room temperature, until the rubber dissolved completely in the solvent. Subsequently $50 \mathrm{phr}$ of nanoclay (Cloisite 20A) was added to the rubber solution and stirring continued. The resultant solution was then cast over in a thoroughly cleaned plane glass plate. The sample was kept in the same condition until the solvent evaporated completely. The obtained film was transparent.

3.2. Compounding. The formulation of the rubber compounds are portrayed in Table 1. The compounds are prepared in open two-roll mixing mill operated at room temperature. The speed ratio of the rotors was 1 : 1.4. The rubber compounds were vulcanized in the compression molding machine at $150^{\circ} \mathrm{C}$, according to the optimum cure time obtained from Monsanto Rheometer.

\section{Characterization Techniques}

4.1. X-Ray Diffraction. The clay gallery height was monitored using an X-ray diffractometer (Philips PANalytical $\mathrm{X}$ 'pert $\mathrm{PRO}$ ) with $\mathrm{Cu}-\mathrm{K} \alpha$ radiation at a generator voltage of $40 \mathrm{kV}$ and wavelength of $0.154 \mathrm{~nm}$ at room temperature. Bragg's law was used to compute the crystallographic spacing (d) of the nanoclays. The range of $2 \theta$ scanning of X-ray intensity employed was $1.5-10^{\circ}$ with a scanning rate of $2^{\circ} \min ^{-1}$.

4.2. High-Resolution Transmission Electron Microscopy (HRTEM). Dispersion morphology of nanoclay in ENR (EC),
TABLe 1: Formulation of the rubber compounds.

\begin{tabular}{cccc}
\hline & \multicolumn{3}{c}{ Designation } \\
Ingredients & SBR & $\begin{array}{c}\text { SBR/5EC } \\
\text { Content (phr) }\end{array}$ \\
\hline Styrene butadiene rubber & 100 & 95 & 90 \\
EC $^{(\text {a) }}$ & - & 5 & 10 \\
Stearic acid & 2 & 2 & 2 \\
CBS $^{(\text {b) }}$ & 0.8 & 0.8 & 0.8 \\
Zinc oxide & 3 & 3 & 3 \\
Sulphur & 2 & 2 & 2 \\
\hline
\end{tabular}

(a) EC: ENR-nanoclay composites;

(b) CBS: N-cyclohexyl-2-benzothiazyl sulphenamide.

EC incorporated in SBR matrix (i.e., SBR/5EC and SBR/ 10EC) are observed in the high-resolution transmission electron microscope (TEM, JEOL 2100). For the HR-TEM observation, ultrathin cross-sections of the specimens were carried out by using a Leica Ultra cut UCT ultramicrotome equipped with a diamond knife. The thickness of the HRTEM specimens was approximately $80 \mathrm{~nm}$ and the temperature of the samples was maintained at $-80^{\circ} \mathrm{C}$ using liquid nitrogen for sample processing. These samples were then placed on the copper grid.

4.3. Dynamic Mechanical Thermal Analysis. Dynamic mechanical properties of the compounds are analyzed using a TA Instrument DMA 2980 model in tension mode. The samples are subjected to a sinusoidal displacement of $0.1 \%$ strain at a frequency of $1 \mathrm{~Hz}$ between the temperatures ranging from $-100^{\circ} \mathrm{C}$ to $100^{\circ} \mathrm{C}$ at a heating rate of $3^{\circ} \mathrm{Cmin}^{-1}$. The storage modulus $\left(E^{\prime}\right)$ and loss tangent $(\tan \delta)$ of the compounds were analyzed.

4.4. Mechanical Testing. Dumbbell and crescent shaped specimens for tensile and tear tests are cut from the molded slabs. Tensile strength was done according to ASTM D-41206 and tear strength was determined according to ASTM D-624-00 (2007) using a Universal tensile testing machine, Hounsfield HS $10 \mathrm{KS}$ model operated at room temperature at an extension speed of $500 \mathrm{~mm} / \mathrm{min}$ with an initial gauge length of $25 \mathrm{~mm}$. The values of tensile strength, modulus, percentage elongation at break and tear strength are recorded directly from the digital display at the end of each test.

\section{Results and Discussions}

5.1. X-Ray Diffraction. The XRD patterns of pure nanoclay, EC, SBR/5EC and SBR/10EC are shown in Figure 1.

The nanoclay (Cloisite 20A) indicated an intense peak around $2 \theta=3.144^{\circ}$, corresponding to the basal spacing of $2.82 \mathrm{~nm}\left(d_{001}\right)$. The EC pattern depicts the $d_{001}$ main diffraction peak, which has been shifted towards the lower angle $2 \theta=2.31^{\circ}$, corresponding to the basal spacing of $3.83 \mathrm{~nm}\left(d_{001}\right)$. This assigns an intercalated structure. Furthermore, along with the main peak, one accompanying peak at $4.67^{\circ}$ corresponding to the basal spacing of $1.90 \mathrm{~nm}$ 


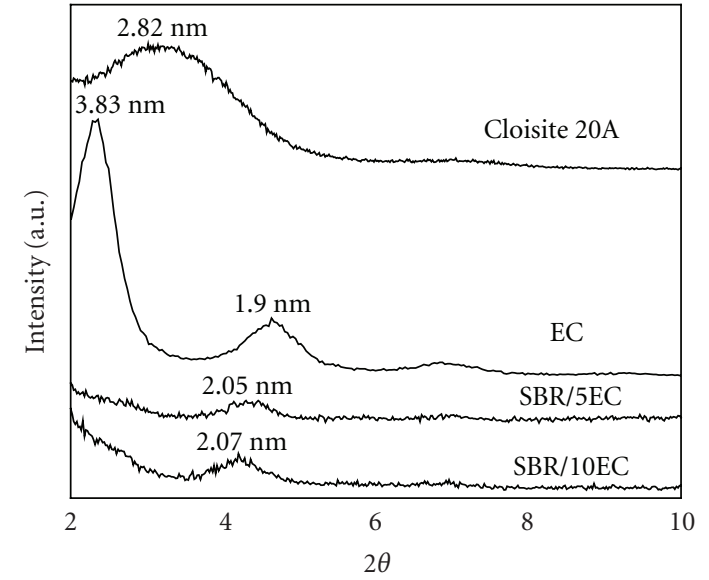

Figure 1: XRD of pure nanoclay (Cloisite 20A), EC, SBR/5EC, and SBR/10EC.

$\left(d_{002}\right)$ arises, due to some reaggregation of nanoclay layers. This peak diminishes relatively to the main peak, which affirms the presence of an intercalated structure [13]. The main peak found in the EC gets completed disappeared, when EC was incorporated in the SBR matrix (i.e., SBR/5EC and SBR/10EC). This proves that the nanoclay is partially exfoliated in the SBR matrix. However both the compounds showed a secondary peak and their intensities get decreased comparatively to that of EC. The formation of secondary peak in the compounds SBR/5EC and SBR/10EC denotes that some part of the nanoclay platelets remains reaggregated, which are apparent in the case of nanocomposites.

5.2. HR-TEM Analysis. The images for the nanocomposites are depicted in Figures 2(a) EC, 2(b) SBR/5EC, and 2(c) SBR/10EC.

The HR-TEM images for the nanocomposites EC, SBR/5EC, SBR/10EC are shown in Figures 2(a)-2(c). Nanoclay clusters are identified in the EC image, the dark lines found indicate the silicate layers. It discloses that bulks of nanoclay dispersion are in the intercalated state, which affirms the better dispersion of nanoclay in ENR. The compounds SBR/5EC and SBR/10EC showed the homogeneous dispersion of nanoclay platelets throughout the SBR matrix. In SBR/5EC, the nanoclays are disorderly oriented in the matrix, providing an evident of exfoliation. The compound SBR/10EC showed that higher percentage of the nanoclay platelets was disorderly oriented and a few are stacked proving the partial exfoliation and formation of agglomerates at few spots in the SBR matrix.

5.3. Dynamic Mechanical Thermal Properties. Figures 3(a) and 3(b) represent the temperature dependence of dynamic storage modulus $\left(E^{\prime}\right)$ and loss factor $(\tan \delta)$, respectively. The increase in loading of EC in the SBR matrix leads to agradual increase in storage modulus compared to pure SBR. The storage modulus of the compound SBR/10EC showed a drop initially than SBR/5EC and the pure one at the lower temperature region (below $-40^{\circ} \mathrm{C}$ ). This may be due to

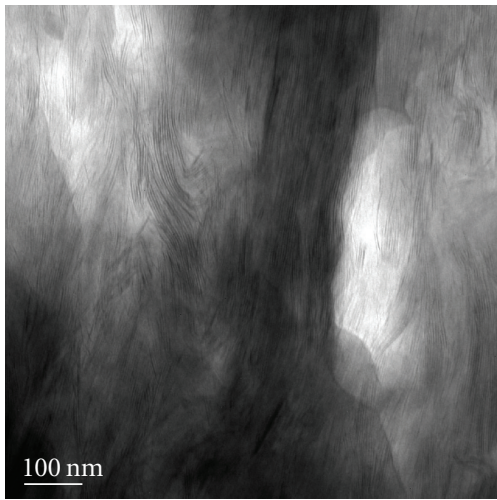

(a)

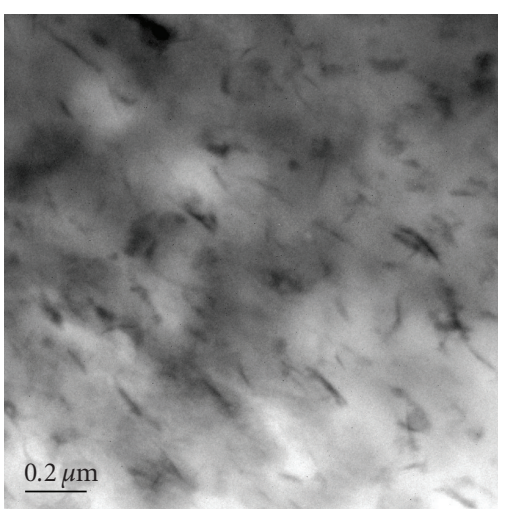

(b)

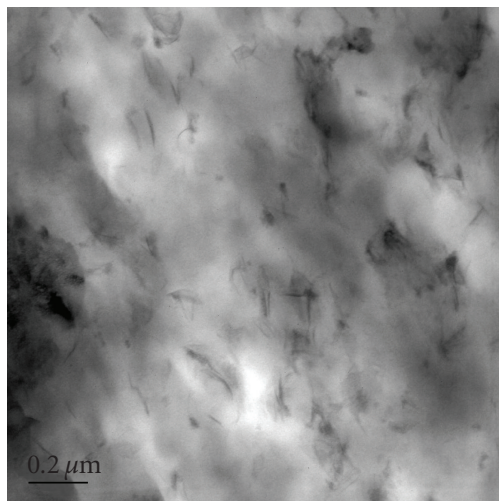

(c)

Figure 2: HR-TEM images of (a) EC, (b) SBR/5EC, (c) SBR/10EC.

higher nanoclay loading that forms agglomeration at few spots in the SBR matrix. The agglomeration can introduce some voids and pores during the sample preparation [14], which may be responsible for decrease in the storage modulus value at the lower temperature region. However, the trend changes with increasing temperature (above $-40^{\circ} \mathrm{C}$ ) as the compounds containing increasing EC loading in SBR matrix showed gradual increase in storage modulus than that of pure SBR. In the rubbery region the polymer-filler, fillerfiller and filler aggregate interactions have a pronounced effect on the storage modulus value [15]. At $25^{\circ} \mathrm{C}$, the compounds SBR/5EC and SBR/10EC show $21 \%$ and $47 \%$ increase in storage modulus compared to pure SBR. 
TABLE 2: Mechanical properties of the rubber compounds.

\begin{tabular}{lccccc}
\hline Sample code & Tensile strength $(\mathrm{MPa})$ & Elongation at break (\%) & 100\% modulus & 300\% modulus & Tear strength (N/mm) \\
\hline SBR & 1.60 & 393 & 0.80 & 1.28 & 7.60 \\
SBR/5EC & 2.95 & 452 & 1.00 & 1.98 & 11.80 \\
SBR/10EC & 3.00 & 454 & 1.03 & 2.10 & 13.40 \\
\hline
\end{tabular}

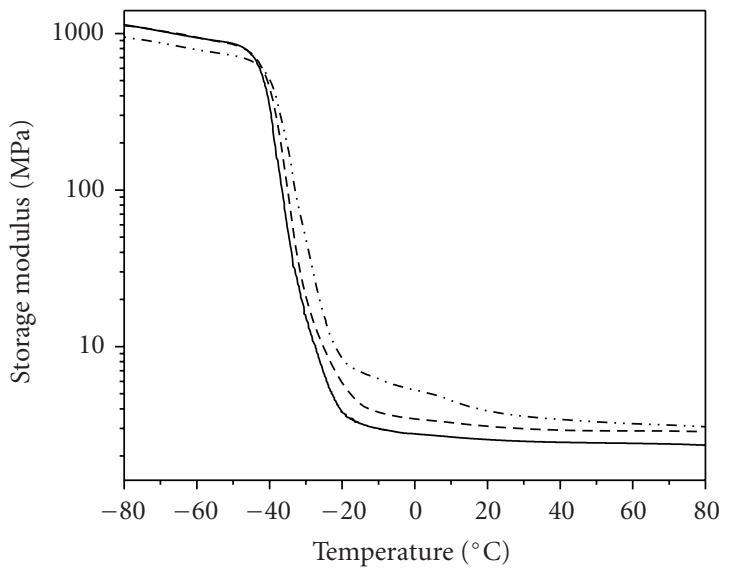

(a)

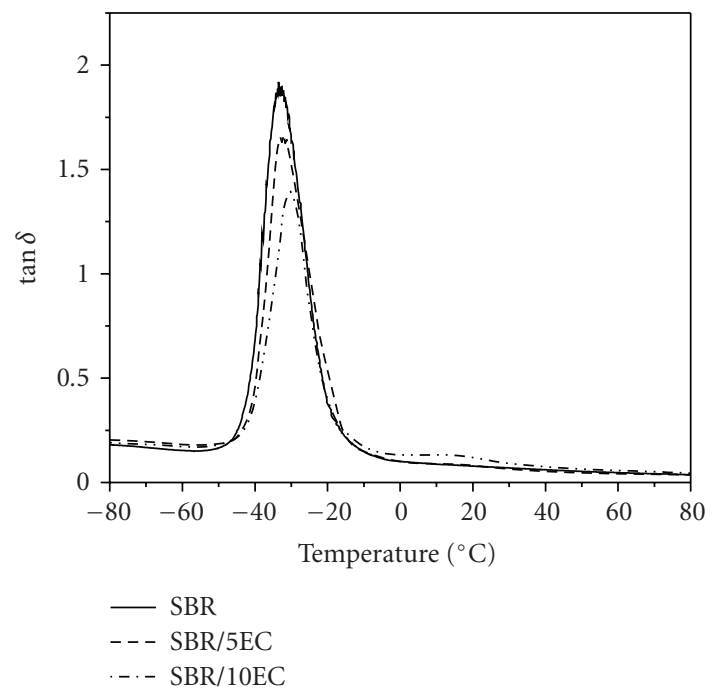

(b)

Figure 3: (a) Storage modulus (b) $\tan \delta$ of SBR, SBR/5EC, and SBR/10EC.

The compounds with increasing EC loading showed gradual decrease in $\tan \delta$ peak compared to pure SBR. This corresponds to reinforcing tendency of the nanofiller in the matrix. Reduced chain mobility owing to physical and chemical adsorption of the SBR molecules on the filler surface causes a height reduction of $\tan \delta$ peak during dynamic mechanical deformation [16]. The decrease in $\tan \delta$ peak proves minimum heat buildup and hence lesser damping characteristics for the compounds containing nanoclay composites. The incorporation of $\mathrm{EC}$ in the compounds SBR/5EC and SBR/10EC showed an increase in glass transition temperature compared to pure SBR. Generally, strong interactions between the nanolayers and the matrix polymer can restrict the movement of polymer segments near to the filler surface, thus resulting in an increase of the glass transition temperature of the matrix [17].

5.4. Mechanical Properties. The mechanical properties of the compounds are depicted in Table 2. The compounds SBR/5EC and SBR/10EC showed $84 \%$ and $87.5 \%$ increase in tensile strength, $55 \%$ and $76 \%$ increase in tear strength, $55 \%$ and $64 \%$ increase in modulus value at $300 \%$ elongation respectively, compared to pure SBR. The percentage elongation at break also increases for the compounds SBR/5EC and SBR/10EC compared to the pure ones. The enhancement in the mechanical properties is due to the better dispersion of EC in the SBR matrix and rubber-filler interaction as corroborated form XRD results and HR-TEM images.

\section{Conclusion}

The morphology of the nanoclay dispersion in ENR by solution mixing demonstrated the intercalation of nanoclay in ENR. Incorporation of EC in SBR matrix forms partial exfoliation of nanoclay in SBR matrix. DMTA results showed an increase in storage modulus and a decrease in $\tan \delta$ value consequently upon increasing EC loading in the SBR matrix, this corresponds to the higher reinforcing efficiency of the nanofiller in the matrix. The overall mechanical properties were enhanced for these particular compounds.

\section{References}

[1] J.-X. Li, J. Wu, and C.-M. Chan, "Thermoplastic nanocomposites," Polymer, vol. 41, no. 18, pp. 6935-6937, 2000.

[2] M. Arroyo, M. A. López-Manchado, and B. Herrero, "Organomontmorillonite as substitute of carbon black in natural rubber compounds," Polymer, vol. 44, no. 8, pp. 2447-2453, 2003.

[3] J. Karger-Kocsis and Z. Zhang, "Structure-property relationships in nanoparticle/semicrystalline thermoplastic composites," in Mechanical Properties of Polymers Based on Nanostructure and Morphology, J. F. Balta Calleja and G. H. Michler, Eds., pp. 547-596, CRC Press/Marcel Dekker, New York, NY, USA, 2005.

[4] M. Arroyo, M. A. López-Manchado, J. L. Valentín, and J. Carretero, "Morphology/behaviour relationship of nanocomposites based on natural rubber/epoxidized natural rubber blends," Composites Science and Technology, vol. 67, no. 7-8, pp. 1330-1339, 2007.

[5] P. L. Teh, Z. A. Mohd Ishak, A. S. Hashim, J. Karger-Kocsis, and U. S. Ishiaku, "Effects of epoxidized natural rubber as a compatibilizer in melt compounded natural rubberorganoclay nanocomposites," European Polymer Journal, vol. 40, no. 11, pp. 2513-2521, 2004. 
[6] S. Varghese, J. Karger-Kocsis, and K. G. Gatos, "Melt compounded epoxidized natural rubber/layered silicate nanocomposites: structure-properties relationships," Polymer, vol. 44, no. 14, pp. 3977-3983, 2003.

[7] R. Rajasekar, T. Das, K. Pal, et al., "Use of ENR / Nanoclay Composites in NR gum compounds," Nano Trends, vol. 3, no. 1, pp. 1-15, 2007.

[8] R. Rajasekar, K. Pal, S. K. Pal, Z. Peng, Y. Chen, and C. K. Das, "Effect of epoxidized natural rubber-nanoclay composites in carbon black filled natural rubber vulcanizates," ICFAI Journal of Science \& Technology, vol. 4, no. 1, pp. 17-29, 2008.

[9] R. Rajasekar, K. Pal, G. Heinrich, A. Das, and C. K. Das, "Development of nitrile butadiene rubber-nanoclay composites with epoxidized natural rubber as compatibilizer," Materials and Design, vol. 30, no. 9, pp. 3839-3845, 2009.

[10] C. Zilg, R. Thomann, R. Mülhaupt, and J. Finter, "Polyurethane nanocomposites containing laminated anisotropic nanoparticles derived from organophilic layered silicates," Advanced Materials, vol. 11, no. 1, pp. 49-52, 1999.

[11] M. Ganter, W. Gronski, P. Reichert, and R. Mulhaupt, "Rubber nanocomposites: morphology and mechanical properties of BR and SBR vulcanizates reinforced by organophilic layered silicates," Rubber Chemistry and Technology, vol. 74, no. 2, pp. 221-235, 2001.

[12] L. Zhang, Y. Wang, Y. Sui, and D. Yu, "Morphology and mechanical properties of clay/styrene-butadiene rubber nanocomposites," Journal of Applied Polymer Science, vol. 78, no. 11, pp. 1873-1878, 2000.

[13] R. A. Vaia and E. P. Giannelis, "Polymer melt intercalation in organically-modified layered silicates: model predictions and experiment," Macromolecules, vol. 30, no. 25, pp. 8000-8009, 1997.

[14] X. Huang, P. Jiang, C. Kim, Q. Ke, and G. Wang, "Preparation, microstructure and properties of polyethylene aluminum nanocomposite dielectrics," Composites Science and Technology, vol. 68, no. 9, pp. 2134-2140, 2008.

[15] V. Sridhar, Studies on the effect of fillers in properties of chlorobutyl vulcanizates, Ph.D. thesis, Indian Institute of Technology, Kharagpur, India, July 2006.

[16] A. Das, F. R. Costa, U. Wagenknecht, and G. Heinrich, "Nanocomposites based on chloroprene rubber: effect of chemical nature and organic modification of nanoclay on the vulcanizate properties," European Polymer Journal, vol. 44, no. 11, pp. 3456-3465, 2008.

[17] H.-H. Huang, G. L. Wilkes, and J. G. Carlson, "Structureproperty behaviour of hybrid materials incorporating tetraethoxysilane with multifunctional poly(tetramethylene oxide)," Polymer, vol. 30, no. 11, pp. 2001-2012, 1989. 

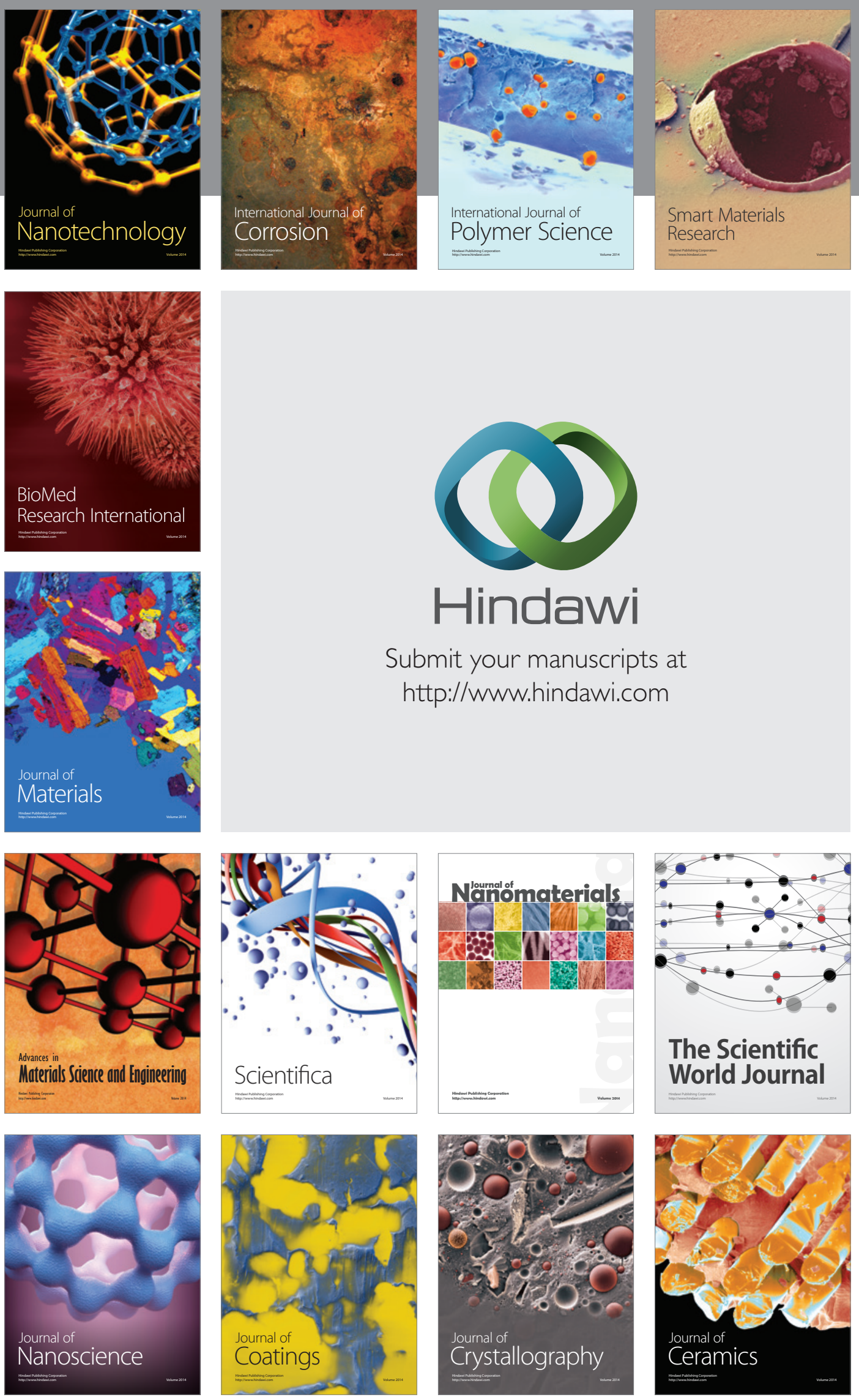

The Scientific World Journal

Submit your manuscripts at

http://www.hindawi.com

\section{World Journal}

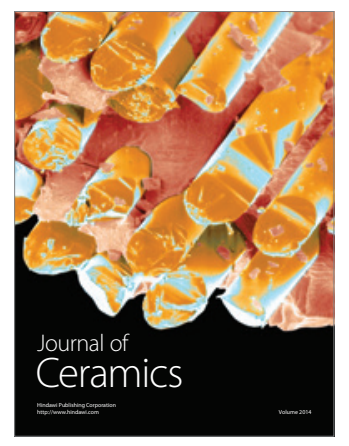

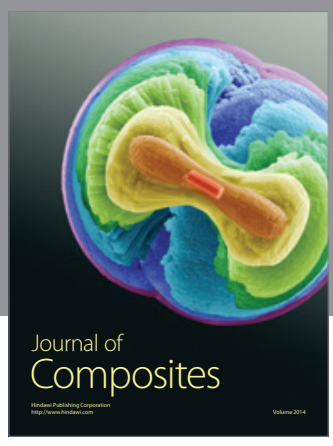
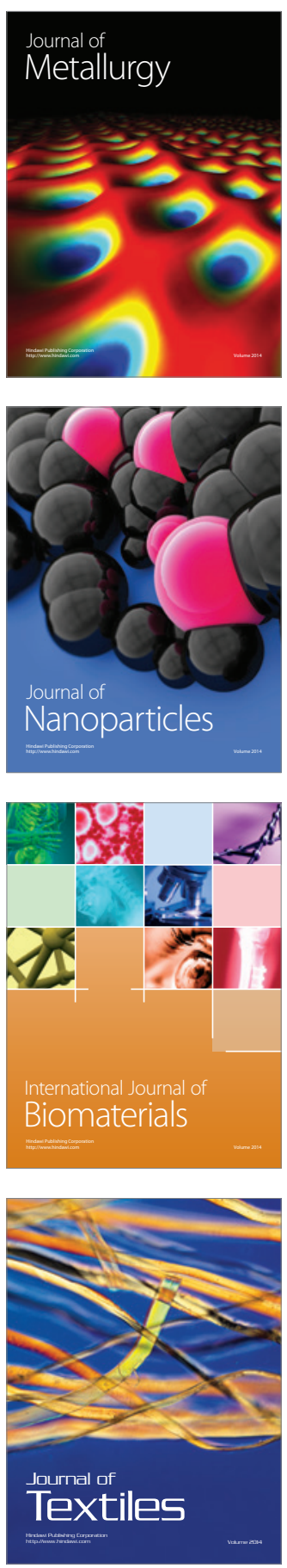